\title{
The Effect of Health Beliefs and Feelings of Self Efficacy on Self Management Behavior of Children With a Chronic Disease*
}

\author{
Noreen M. Clark ${ }^{a}$, Irwin M. Rosenstock ${ }^{a}$, Halimah Hassan ${ }^{b}$, \\ David Evans ${ }^{c}$, Yvonne Wasilewski ${ }^{c}$, Charles Feldman ${ }^{c}$ and \\ Robert B. Mellins ${ }^{c}$ \\ ${ }^{a}$ Department of Health Behavior and Health Education, University of Michigan School of Public \\ Health. 'Institute for Social Research. University of Michigan, Ann Arbor, MI and Department of \\ Pediatrics, Columbia University College of Physicians and Surgeons, New York, NY (U.S.A.)
}

(Received July 14th, 1987)

(Accepted November 16th, 1987)

\begin{abstract}
This study is among the first to examine the value of chronically ill children's health beliefs, selfefficacy beliefs, experiences of hospitalization, and participation in a health education program in predicting self-management behavior. Data were collected from a random sample of 214 children with asthma being served by any of four NYC hospitals. As measured, perceived self-efficacy, prior hospitalization and participation in a health education program had modest predictive value for selfmanagement while measures of perceived severity of asthma attacks and beliefs in the benefits of self-management techniques in controlling the disease failed to predict subsequent use of selfmanagement techniques. We conclude that (1) the Health Belief Model may not be useful in predicting the behavior of children because of their developmental status, or (2) the measures used in the present study did not adequately tap the health belief constructs.
\end{abstract}

Key words: health heliefs, self-management; self-efficacy

\section{Introduction}

The study reported here is unique in that it combined elements of the health belief model and social learning theory to see if they were useful in predicting disease management behavior of low-income children with asthma. The study was based on data collected directly from children.

Collecting data from children themselves has proved important. Recent reviews by Lewis and Lewis [1] and Clark and Shope [2] have illustrated that

\footnotetext{
*The work described in this paper was supported in part by grant number 1-R18-HL-28907 from the Lung Division, National Heart, Lung and Blood Institute, and a gift from the Spunk Fund.
} 
there are few studies which describe the psychosocial features associated with the health behavior of healthy children or disease management behavior of children with a chronic illness.

Further, most studies are based on data collected from parents. Lewis et al. [3] and Campbell [4-6] showed that health beliefs reported by children differed from their parents' beliefs, and from the parents' accounts of their children's beliefs. Lewis et al. [3] also found that children observed in an adult-free setting sought health services at a different frequency and for different reasons than their parents sought services for them. Parent reports were not necessarily accurate regarding their children's health beliefs and independent behaviors.

\section{The Health Belief Model}

The health belief model (HBM) has been used extensively as a framework for studying adult health and illness behavior [7]. The model posits that actions related to preventing health problems and managing existing conditions can be predicted on the basis of a person's beliefs about (a) the severity of the problem, (b) one's susceptibility to the problem, and (c) the benefits and barriers to desired actions [7]. Only two recent studies have used the HBM as a basis for conceptualizing children's views and actions regarding their own health $[8,9]$. Dielman et al. [8] in a study of the relationship between parent and child beliefs and behaviors demonstrated that a healthy child's perceived susceptibility to specific disease was correlated with the child's age.

Gochman and Saucier [9] found that healthy children's beliefs about their vulnerability to disease were consistent across health problems; children who believed themselves susceptible to one minor health problem also believed themselves vulnerable to other minor health problems. Among girls nine to thirteen years of age, beliefs in vulnerability and attitudes toward prevention were positively associated. Among adolescents, however, higher levels of perceived vulnerability were correlated with lower levels of preventive attitudes.

Kirscht et al. [10] have questionned belief in severity as an independent determinant of health behavior in adults and suggested that belief in susceptibility is a better predictor. However, the investigators were studying populations free of chronic conditions. In several studies [7] belief in severity has proved to be a determinant of adult health and illness behavior.

In the current study, we chose to examine belief in severity and not to examine susceptibility. All children in our study were diagnosed as having asthma and were aware of their diagnosis. We reasoned, therefore, that most would view themselves as susceptible to the illness.

\section{Social learning theory}

A number of investigators have empirically tested the prediction from social learning theory that whether a behavior will be performed depends upon outcome expectations (the belief that a given behavior will lead to given outcomes) as well as upon efficacy expectations (the belief that one is capable of executing a particular behavior needed to influence an outcome) [11]. (It should 
be noted that the HBM 'perceived benefits' construct is identical with the 'outcome expectation' construct in social learning theory.) In recent reviews, 0'Leary [12] and Strecher et al. [13] found extensive evidence to support the theory. Few investigations regarding self-efficacy to date, however, have dealt with disease management and none have focused on chronically ill children, although the social learning theory from which the concept derives is generally considered to apply to children above the age of 6 or 7 as well as adults.

In the current study, we were also interested in the extent to which prior hospitalization as well as participation in self-management education influenced the management behavior of children during a subsequent asthma attack. A previous study [14,15] of children with asthma demonstrated that the experience of hospitalization was a profound one for families; those children who had a prior in-patient stay were the ones to significantly reduce hospital and emcrgency room visits following participation in an educational program designed to improve family self-management of asthma.

\section{Health beliefs and social learning}

No previous study has examined concurrently components of the health belief model and the construct of self-efficacy. We expected that they would be significant predictors of self-management, although predictive power may vary. Our first study hypothesis was that three beliefs would characterize higher levels of management activity by children at the time of an asthma attack. These beliefs were that: the chronic disease was serious, selfmanagement in general would help to control wheezing (outcome expectation), and one was capable of doing something to prevent illness (efficacy expectation). The second study hypothesis was that children who had been hospitalized, those who had taken part in self-management education, and those who were older would show higher levels of self-management activity during an asthma attack.

\section{Methods}

\section{Study sample}

The sample included 214 children between 7 and 17 years of age from among those who had participated in a larger study of health education and who attended allergy clinics in four New York City Hospitals. In order to be eligible for the study, the children had to have a physician's diagnosis of asthma and to have made at least one clinic visit for the disease in the previous year. Of the 558 children who fit criteria for the larger study, 368 could be contacted after three attempts. The reason for non-contact was primarily that families had moved and/or no longer used clinic services. Of this number, 310 agreed to participate, and 214 children were seven years or older and completed the interview process making them eligible for the study presented here. An hourlong baseline interview was conducted and a follow-up interview administered 1 year later. Both interviews coincided with a regularly scheduled clinic visit. 
Following the baseline interviews, two-thirds of the children were randomly assigned to and participated in a formal health education program [16].

The sample was intended to represent the clinic population of children who sought services for asthma. To check for the representativeness of the sample, we compared data on those enrolled in the study regarding age, sex, ethnicity, and distance of residence from the hospital with those who could not be located or no longer used clinic services. Using the same variables, we also compared participants with those who refused to participate. No significant differences were found in these comparisons with the exception of age. Children who could not be located or no longer attended clinics were slightly older (mean age 11.0 vs. 9.2, $P<0.05$ ) than participants. This difference probably reflects the fact that as children get older they tend to experience fewer asthma symptoms and use clinic services less frequently. Based on these analyses, the sample appears to represent the pediatric allergy clinic population using services for asthma. Sixty-four percent of the children were male. Families were predominantly $(80 \%)$ black or Hispanic. The majority received public assistance.

\section{Data analysis}

Model I. Three theoretical models were constructed to test relative influence on self-management of non-behavioral variables compared to belief and behavioral variables. Model one included beliefs and behaviors. Children's belief in the severity of the asthma as assessed by responses to three dichotomous interview items: (1) whether or not they believed the disease interfered with the ability to play, (2) damaged the lungs, and (3) could be fatal. Belief in self-management was assessed by determining the extent to which a child agreed with each of four questionnaire items describing the benefits of taking management actions.

The child's perception of self-efficacy to prevent illness was determined by the response to a single questionnaire item 'if I am going to be sick, nothing I do will stop me from getting sick'. We recognize that a single item measure of selfefficacy is not the preferred aproach, but time constraints precluded more intensive measures. (See O'Leary Ref. 12 for an analysis of methods for assessing self-efficacy.) It may be argued that the present item more nearly measured locus of control than self-efficacy. The distinction between these concepts has been the source of a continuing and unresolved debate between Kirsch [17,18] and Bandura [19]. We were satisfied that the present item adequately tapped a child's feelings of competence to act in the face of a wheezing episode.

The measure of children's management behavior at baseline and follow-up was a score of $0-4$ based on the number of management actions each reported undertaking at the time of the last wheezing episode: taking medicine, resting, telling parent or caretaker, drinking fluids. We expected that children who engaged in self-management behavior at baseline would continue to do so at follow-up.

Model II. The second model was comprised of three non-behavioral variables which previous research had shown to be influential in self- 
management of wheezing episodes $[15,16]$. First, was the child's age. The older the child the higher the level of self-management we expected. Second, was whether or not the child had ever been hospitalized for asthma. Third, was whether or not a child had participated in the health education program which encouraged self-management.

Model III. The third model was a combination of models one and two constructed to compare the relative effects of cognitive and non-cognitive factors on self-management behavior.

The hypotheses were tested by means of ordinary least squares multiple regressions. Time two management behavior was regressed against all variables in each model. We will also report bivariate relationships among the predictor variables using the correlation matrix of the regression. The criterion of statistical significance was set at $P<0.05$.

\section{Results}

Table I presents findings from the regression analyses of the three models. Model I relates to children's health beliefs and behaviors. In this model, children's perceptions that they were self-efficacious, that is, able to prevent or mitigate the effects of illness, were significantly associated with their subsequent management behavior $(P=0.02)$. No other beliefs or behaviors were associated with subsequent management at a statistically significant level. The model accounted for just $3 \%$ of the variance in management behavior.

In model II (non-behavioral factors), both a previous hospitalization and participation in the health education program were significantly associated with self-management behavior at $P=0.001$ and $P=0.007$, respectively. The entire model explained only $7 \%$ of the variance.

Model III explained the greatest fraction of variance at $10 \%$. When all

\section{TABLE I}

STANDARDIZED REGRESSION COEFFICIENTS OF VARIABLES IN THREE MODELS USED TO PREDICT SELF-MANAGEMENT OF SUBSEQUENT ASTHMA ATTACKS

\begin{tabular}{|c|c|c|c|c|}
\hline & & \multicolumn{3}{|c|}{ Behavior in managing subsequent attack } \\
\hline & & Model I & Model II & Model III \\
\hline (1) & Perceived severity of disease & 0.11 & & 0.07 \\
\hline (2) & $\begin{array}{l}\text { Self-management perceived to be } \\
\text { beneficial }\end{array}$ & -0.11 & & $-0.14^{*}$ \\
\hline (3) & Perceived self-efficacy & $0.16^{*}$ & & $0.16^{*}$ \\
\hline (4) & Behavior in managing earlier attack & 0.00 & & 0.03 \\
\hline (5) & Participated in health education & & $0.25^{*}$ & $0.22^{*}$ \\
\hline (6) & Had previous hospitalization & & $0.19^{*}$ & $0.21^{*}$ \\
\hline \multirow[t]{2}{*}{ (7) } & Age & & -0.06 & -0.02 \\
\hline & R-squared & 0.03 & 0.07 & 0.010 \\
\hline
\end{tabular}

$* P<0.05$. 
variables are considered, three were significant predictors of subsequent management behavior: perceiving oneself to be efficacious in preventing or reducing the impact of illness $(P=0.02)$, having participated in health education $(P=0.002)$, and having had a previous hospitalization $(P=0.003)$. The belief that self-management is beneficial was inversely related to subsequent management behavior at a statistically significant level $(P=0.05)$. Baseline self-management actions were not significantly associated with followup self-management actions.

Several other interesting associations were evident in the data (Table II). Believing that self-management is beneficial was positively associated with behavior in managing an earlier attack $(r=0.16, P=0.02)$ and with having had a previous hospitalization $(r=0.16, P=0.05)$. Perceived severity of disease was inversely associated with age $(r=-0.31, P=0.00005)$.

\section{Discussion}

These data suggest that the concept of self-efficacy is a useful predictor of subsequent disease management behavior of children. Contrary to our expectations, the concept of severity did not predict self-management behavior. As previously indicated, baseline self-management behavior was not significantly associated with behavior at follow-up, and baseline belief in selfmanagement was inversely associated with subsequent management of a wheezing episode.

\section{Instability of children's beliefs}

These latter findings are puzzling and not explainable by available data. Speculation, however, suggests a number of plausible explanations. This is the first study, to our knowledge [2], to examine elements of the health belief model as predictors of chronically ill children's disease management behavior. In his longitudinal study, Mechanic [20] found low levels of continuity in patterns of illness behavior, especially in children. He suggested that health beliefs and behavior of children are not stable over time. Similarly, Dielman et al. [21] and Radius et al. [22] provide data to support the view that there is 'decreasing variability in health beliefs with increasing age', and that 'by age 12 certain (health) beliefs are largely established'. If instability of health beliefs is characteristic of younger children, one might not expect beliefs to predict behavior measured a year later.

This interpretation is supported by our findings that belief in selfmanagement was positively correlated with management behavior during an earlier attack but not in a subsequent attack. Indeed, prior management behavior may be a partial determinant of subsequent beliefs. Health beliefs and behavior may change as children experience wheezing episodes, participate in education, and grow older. In his study of healthy children, Gochman [9] found that perceptions of vulnerability were inversely related to age among adolescents and this too lends support to the notion that health beliefs may not be stable enough to predict subsequent behavior before adulthood. 


\section{Developmental stage}

Another related interpretation is that concepts of severity and benefits of self-management may have been too abstract for the children studied. The average age of sample children was 9 , the age described by Piaget [23] as the concrete operational stage and characterized by some difficulty in abstract thinking. It is clear from these data that being hospitalized and participating in health education, two very concrete experiences for children, were the most powerful predictors of their subsequent behavior. Compared with the concrete experiences of hospitalization and education, abstractions such as health beliefs may not constitute the compelling infuence on children they have often been shown to constitute for adults.

\section{Adequacy of measures}

It is also quite possible that the measures we developed to assess severity belief and belief in self-management were simply inadequate. The items may not have tapped the children's true beliefs or may not have captured the precise nature of beliefs that would determine subsequent management behavior. The variance accounted for by the most powerful model was only $10 \%$. Better indices of belief might not only show positive relationships but might account for a greater fraction of the variance in explaining management behavior.

\section{Conclusions}

Self-efficacy, participation in health education, and experiencing a hospitalization appear to be predictors of self-management behavior in the chronically ill child. Given the extensive literature on the influence of health beliefs on health behavior of adults, future research should focus on the development of more precise measures of health beliefs of chronically ill children and should examine (1) the way in which health beliefs are formed by children and change over time and (2) the influence of health beliefs of children at different ages on subsequent disease management behavior.

\section{Implications for practitioners}

Study findings are particularly important for health educators, nurses, and counselors working with children. Educational programs frequently try to increase children's perceptions of the seriousness of their illness and value they place on self-management. Our data suggest that these perceptions and values are not major influences on a child's behavior. Bolstering a child's feelings of self-efficacy may be a more effective educational strategy especially for those who have experienced hospitalization.

Our findings also identify those at risk for low levels of at-home management of their chronic disease: children who have been hospitalized and express little confidence in their ability to mediate the effects of illness. These children constitute the priority target population for health education, which as demonstrated, has a positive effect on subsequent levels of self-management. 
Further, findings suggest to practitioners that the timing of interventions is important. If health beliefs during childhood are somewhat unstable then education must be provided over time to support management behaviors. To enable beliefs and skills to take hold, education with frequent follow-up which accounts for the changing child should be the standard of practice.

\section{Acknowledgment}

The authors are grateful to Dr. Yuzuru Takeshita and Dr. Jack Kirscht for their assistance in the preparation of this paper.

\section{References}

1 Lewis CE, Lewis MA. Improving the health of children: Must the children be involved? Annu Rev Public Health 1983; 4: 259-83.

2 Clark NM, Shope J. The current knowledge base for health education programs for chronically ill children. Adv Health Educ Prom 1(B) 1986; 397-434.

3 Lewis CE, Lewis MA, Lorimer A, Palmer BB. Child-initiated care: The use of school nursing services by children in an "adult-free" system. Pediatrics 1977; 60: 499-507.

4 Campbell JD. Attribution of illness: Another double standard. J Health Soc Behav 1975; $16: 114$ $-126$.

5 Campbell JD. The child in the sick role: Contributions of age, sex, parental status, and parental values. J Health Soc Behav 1978; 19: 35-51.

6 Campbell JD. Illness is a point of view: The development of children's concepts of illness. Child Dev 1975; 46: $92-100$.

7 Janz N, Becker MH. The health belief model: A decade later. Health Educ Q 1984; 11(1): $1-47$.

8 Dielman TE, Leech S, Becker MH, Rosenstock IM, Horvath WJ, Radius SM. Parental and child health beliefs and behavior. Health Educ Q 1982; 9(2,3): 60-77.

9 Gochman D, Saucier J.-F. Perceived vulnerability in children and adolescents. Health Educ Q $1982 ; 9(2,3): 46-59$.

10 Kirscht JP, Haefner DP, Kegeles SS, Rosenstock IM. A National study of health beliefs. J Health Human Behav 1966; 7: 242-254.

11 Bandura A. Social Foundations of Thought and Action: A Social Cognitive Theory. Englewood Cliffs, NJ: Prentice-Hall, 1986.

12 O'Leary A. Self-efficacy and health. Behav Res Ther 1985; 23(4): 437-451.

13 Strecher VJ, DeVellis BM, Becker MH, Rosenstock IM. The role of self-efficacy in achieving health behavior change. Health Educ Q 1986; 13(1): 73-79.

14 Clark NM, Feldman CH, Evans D, Duzey O, Levison MJ, Wasilewski Y, Kaplan D, Rips J, Mellins RB. Managing better: Children, parents, and asthma. Patient Educ Couns 1986; 8: $27-$ 38.

15 Clark NM, Feldman CH, Evans D, Levison MJ, W asilewski Y, Mellins RB. The impact of health education on frequency and cost of health care use by low income children with asthma. J Allergy Clin Immunol 1986; 78: 108-115.

16 Clark NM, Feldman CH, Freudenberg N, Millman EJ, Wasilewski Y, Valle I. Developing education for children with asthma through study of self-management behavior. Health Educ $Q$ $1980 ; 7(4): 278-297$.

17 Kirsch I. Efficacy expectations or response predictions: The meaning of efficacy ratings as a function of task characteristics. J Pers Soc Psychol 1982; 42: 132-136.

18 Kirsch I. Self-efficacy and expectancy: Old wine with new labels. J Pers Soc Psychol 1985; 49: $824-830$.

19 Bandura A. Self-efficacy determinants of anticipated fears and calamities. J Pers Soc Psychol $1983 ; 45: 464-469$. 
20 Mechanic $D$. The stability of health and illness behavior: Results from a sixteen year followup. AJPH 1979; 69: 1142-1145.

21 Dielman TE, Leech SL, Becker MH, Rosenstock IM, Horvath WJ. Dimensions of children's health beliefs. Health Educ Q 1980; 7(3): 219-238.

22 Radius SM, Dielman TE, Becker MH, Rosenstock IM, Horvath WJ. Adolescent perspectives on health and illness. Adolescence 1980; 25(58): 375-384.

23 Schwebel M, Raph J. Piaget in the Classroom. New York: Basic Books, Inc., 1973. 